TAO, Vol. 12, No. 4, 663-684, December 2001

\title{
Acoustic Calibration of Echo Soundings: Applications in Shelf Region off Northern Taiwan
}

\author{
Gwo-Shyh Song ${ }^{1, *}$ and Kuang-Yui Chen ${ }^{1}$ \\ (Manuscript received 18 May 2001, in final form 20 September 2001)
}

\begin{abstract}
With a preset echo sounding velocity, each bathymetric measurement can be corrected off-line numerically. This article presents an iteration algorithm of acoustic calibration for a representative acous tic profile versus depth of water column obtained in the survey area. In addition, different kinds of acoustic profile, represented by polynomial regression equations, were addressed offs hore north Taiwan. Results gave a large variety of patterns in acoustic profile within a small limit of territories in the shelf region, indicating that bathymetric measurements collected off northern Taiwan should be calibrated with much care. However, using an expected mean velocity at $1525 \mathrm{~m} / \mathrm{s}$, sounding accuracy with deviation less than $0.2 \%$ was obtained on the shelf in the summer.
\end{abstract}

(Key words: Bathymetry, Acoustic correction, Acoustic profiles, Offshore northern Taiwan)

\section{INTRODUCTION}

Echo sounders measure water depth by generating a pulse of sound, and receiving its echo from the bottom. The time that it takes the sound to travel between the water surface and bottom allows us to calculate the range to the bottom or the thickness of the water column, by knowing this time and the speed of the sound in water (called echo time and acoustic velocity, hereinafter).

Acoustic velocity depends on the water temperature, pressure and salinity, and these must be known at a sufficient number of points in the water column before an echo sounding can be derived. However, whilst bathymetry is obtained as under-way geophysical data, it has been very seldom that the temperature and salinity could be measured at time of echo sounding. Under this circumstance, either an estimated mean velocity was presumed (conventionally at $1,500 \mathrm{~m} / \mathrm{sec}$ ) to compute so-called the observed water depths, or the observed depths would be calibrated by a certain defining empirical formula; like the Matthews Tables (Matthews 1939),

\footnotetext{
${ }^{1}$ Institute of Oceanography, National Taiwan University, Taipei, Taiwan

* Corresponding author address: Prof. Gwo-Shyh Song, Institute of Oceanography, National Taiwan University, P. O. Box 23-13, Taipei, Taiwan, 106; E-mail: Song@gssong.oc.ntu.edu.tw
} 
or the GEBCO Third Edition Echo-Sounding Tables (Carter and Sherwood 1980).

In recent years, besides the multi-beam echo sounding data, the demand for very precise single-beam sounding measurement has been desired (IHO 1996). Especially for surveys conducted in shallow water areas (less than $100 \mathrm{~m}$ ), for a sounding accuracy of less than $0.5 \%$ relative to its measured depth was called (IHO 1987). Instead, the Matthews and Third Edition Tables are applicable only for use in areas with water depths greater than $200 \mathrm{~m}$ (Carter and Sherwood 1980), because that there are apparent variations of acoustic velocities resulting from local and seasonal changes in the temperature and salinity. This variation is so large that tabular acoustic velocities can be incorrect to as much as $2.5 \%-3 \%$ in the upper water column (Matthews 1939; Shyu 1982).

In areas with greater water depths, if acoustic velocities versus depths in a water column are known, an adjusted depth can be obtained by adding a required correction to its measured depth given initially by a $1500 \mathrm{~m} / \mathrm{sec}$ mean velocity. Every required correction value is then estimated by a polynomial curve fitted through the least-squares method (Lu et al. 1978; Hsu et al. 1996). However, Shyu $(1982 ; 1984)$ indicated that there were variant deviations of correction at depths shown by his model. It was, for example, about $1.5 \%$ deviation of the measured depth at $540 \mathrm{~m}$ in water offshore eastern Taiwan, compared with those estimated by the Matthews Tables of the Area 41, which covers the western part of the Pacific Ocean (Matthews 1939).

The region offshore northern Taiwan, mainly occupies the territory in the shelf regions of so-called the East China Sea Shelf and the Chilung Shelf (Yu and Song 1993; Song et al. 1997; Liu et al. 1998). Those correction tables are not suitable for these shallow underwater areas. Consequently, a check by wire sounding was used for several decades when greater accuracy was necessary in shallow water (Matthews 1939). Until recent years, an analogue calibration method called Bar Check, which determines a mean acoustic velocity to coincide exactly with the distance between transducer and a steel reflector plate attached to a rope in still water insitu, was generally used before conducting single-beam echo sounding (Honeywell 1990). However, these would easily suffer from using an incorrect mean velocity due to the sounding usually being in the water at variant depths, the wire or attached rope may not go straight down to the deep, or the calibration reflector may not be parallel to the transducer surface.

Offshore the Taiwan region, there has been to an increase in amount of bathymetric data without conducting proper acoustic calibration to measurements, in part because they belonged usually to underway ship-track data sets. According to Shyu's (1982) study, there were also seasonal effects on the amount of correction at each station; his study demonstrated correction differences among three stations located in the offshore region of northeastern Taiwan. In order to gain precision in those underway-bathymetric measurements, the algorithm of acoustic calibration is here demonstrated. We just defined several types of acoustic velocity profile according to hundreds of the CTD measurements collected in the period of early 1990s off northern Taiwan.

\section{DATA AND METHOD}

The CTD measurements in the data bank of the Ocean Science Research Center, National 
Science Council in Taiwan collected before 1994 were reviewed. Over eight hundred of them had been taken in the area off northeastern Taiwan (Song and Chen 1994). At each station the CTD probe measured the temperature, salinity and pressure values throughout water column, then acoustic velocities at each selected depth could be estimated at 1-10 m intervals with standard deviation less than $0.05 \mathrm{~m} / \mathrm{sec}$, respectively (Del Grosso 1973; Shyu 1982). As a result, the profiles in terms of acoustic velocity versus depth (acoustic profile is called, hereinafter) were obtained and compared with each other in the study.

In certain particular offshore areas some typical acoustic profiles were picked and sorted out for the study. Using the least-squares method, any group of acoustic profiles can be regressed and represented by a k-order polynomial equation:

$$
V(d)=\sum_{n=0}^{k} a_{n} d^{n},
$$

where $v(d)$ is the expected velocity at depth $d$, and $a_{n}$ is coefficient at nth order. As soon as a defining type for a group of acoustic profiles is determined under the condition of the percentage of residuals about regression mean (or the correlation coefficient) being greater than at least $90 \%$, a k-order polynomial is obtained. The condition delivers a fitted polynomial curve that stands for a particular type of acoustic profile, and the respective values of regression coefficient $\mathrm{a}_{\mathrm{n}}$ are given.

As a result, a fitted polynomial is a candidate for the role of calibrating suitable bathymetric measurements. In other words, every observed water depth collected by the single-beam echo sounder in a given region for a selected season can be numerically corrected with a represented polynomial in terms of equation (1) by the following steps as below, respectively:

1) Calculate $\mathrm{d}_{1}=\left[\mathrm{a}_{\mathrm{o}}+\mathrm{a}_{1} \mathrm{~d}_{\mathrm{m}} / 2+\mathrm{a}_{2} \mathrm{~d}_{\mathrm{m}}{ }^{2} / 3+\ldots+\mathrm{a}_{\mathrm{k}} \mathrm{d}_{\mathrm{m}}{ }^{\mathrm{k}} /(\mathrm{k}+1)\right] \mathrm{d}_{\text {mcasure }} / \mathrm{v}_{\text {set }}$, where Vset is the acoustic velocity constant setting in the survey.

2) Replace $d_{m}$ by $d_{1}$ in equation of step (1), the value of $d_{1}$ is revised.

3) Turn the revised $d_{1}$ as the value of $d_{2}$, and replace $d_{m}$ by $d_{2}$, then repeat the calculation in step (1) to obtain a revised $d_{2}$ value.

4) Iterate through the process shown in step (3), $d_{3}, d_{4}, d_{5}, \ldots d_{i}, d_{i+1}$ are obtained, calculations stop when $\left|d_{i+1}-d_{i}\right|<<\varepsilon$, where $\varepsilon$ is a minimal.

5) Obtain a required depth $d_{i+1}$ corrected from observed water depth of the measurement $d_{\text {measure' }}$, which gives an initial value of $d_{m}$ in the first step.

\section{TYPES OF ACOUSTIC PROFILES OFF NORTHERN TAIWAN}

The offshore area of northern Taiwan is located in the territory of continental shelf, divided transversely by a valley and a canyon, respectively, into three physiographic units east of $121^{\circ} 40$ 'E: a coastal zone, the Chilung Shelf, and the East China Sea Shelf (Fig. 1). The Chilung Shelf, featuring with a rough shelf surface ranging at $140 \mathrm{~m}-220 \mathrm{~m}$ that is deeper than a typical shelf, is situated in between the Chilung Sea Valley and the Mien-Hua Submarine Canyon (Song et al. 1997; 2000). Across the canyon to the north, the East China Sea Shelf in the study area features with a rather smooth and typical shelf floor of water depths around 120 


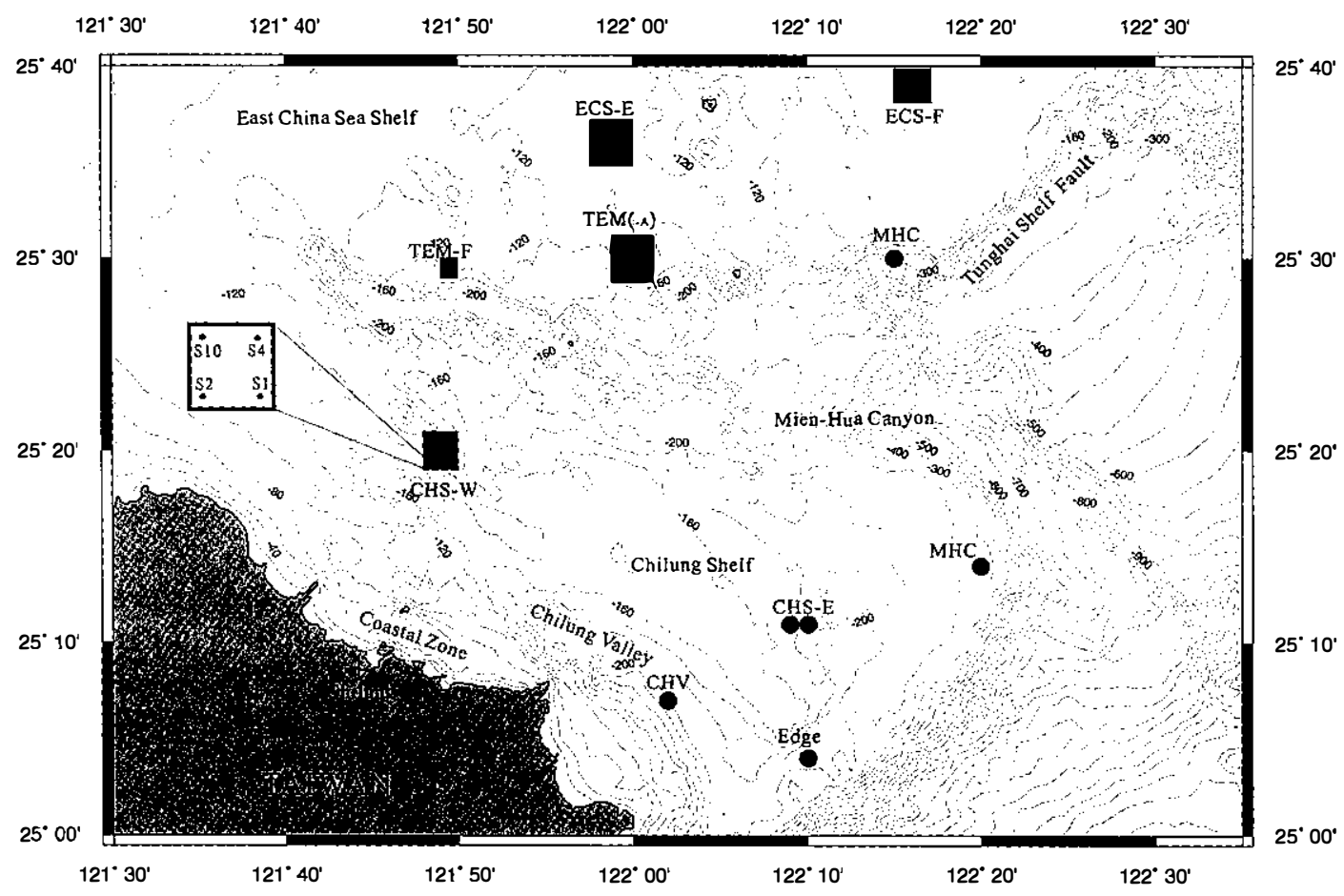

Fig. 1. Location diagram of the study area. Background is bathymetric contours produced using the commands in GMT (Wessel and Smith, 1991). Physiographical units are indicated. Solid squares denote the locations of defined acoustic types in the study; the size of square stands for the area occupied. The inset shows the relative sites of the CTD stations distributed in the CHS-W area.

m. In the Chilung Shelf, the Mien-Hua Canyon bounds it on the north, which is well developed and truncated deeply into the continental slope off shelf break; and the Chilung Sea Valley bounds it on the south, which stretchs northwest against the coast zone and appears only on the shelf territory (Song and Chang 1993).

Offshore northern Taiwan, different types of acoustic profile were recognized according to the places in which these profiles were sampled. In addition, most of them belong merely to the summer type, because they were determined using the CTD measurements deployed in the July and August. Represented locations are classified and shown in Fig. 1 and listed in Table 1.

\subsection{ECS Type}

This type of acoustic profile, called the East China Sea type, displays traces in the variety shown in Fig. 2a. These profiles were taken in the East China Sea Shelf of territories mainly away from the Mien-Hua Canyon. Although a $5^{\text {th }}$ order polynomial curve denoted in Fig. 2a 
Table 1. Area descriptions table. The deployed dates of the CTD measurements are noted in the Period of Data Collection column. Depth Limitations were determined according to the value of maximum depth of acoustic profiles included in the specified area. Good of fitness is the percentage value regarding to the residual about its regression mean; $100 \%$ stands for a perfect match, and $0 \%$ for non-relative.

\begin{tabular}{|c|c|c|c|c|}
\hline $\begin{array}{c}\text { Area (or Type) } \\
\text { Name }\end{array}$ & $\begin{array}{c}\text { Sub-area } \\
\text { Name }\end{array}$ & $\begin{array}{c}\text { Period } \\
\text { of } \\
\text { Data Collection }\end{array}$ & $\begin{array}{c}\text { Depth Limitation } \\
\text { of } \\
\text { Calibration }\end{array}$ & Fitness (\%) \\
\hline \multirow{3}{*}{ ECS } & ECS & $\begin{array}{c}12^{\text {th }} \sim 14^{\text {th }} \text { July, } 1992 \\
4^{\text {th }} \text { Sept., } 1991\end{array}$ & $120 \mathrm{~m}$ & 96 \\
\hline & ECS-E & $14^{\text {th }}$ July, 1992 & $110 \mathrm{~m}$ & 99 \\
\hline & ECS-F & $7^{\text {th }}$ Oct., 1991 & $120 \mathrm{~m}$ & 98 \\
\hline MHC & N/A & $\begin{array}{l}2^{\text {nd }} \text { Aug., } 1991 \\
11^{\text {th }} \text { Aug., } 1992\end{array}$ & $360 \mathrm{~m}$ & 99 \\
\hline \multirow{3}{*}{ TEM } & TEM & $\begin{array}{c}1^{\text {st }} \sim 5^{\text {th }} \text { Aug. } \\
1990,1991\end{array}$ & $120 \mathrm{~m}$ & 97 \\
\hline & TEM-A & $\begin{array}{c}1^{\text {st } \sim 5^{\text {th }} \text { Aug. }} \\
1990,1991 \\
\end{array}$ & $120 \mathrm{~m}$ & 93 \\
\hline & TEM-F & $23^{\text {th }}$ Sept., 1990 & $140 \mathrm{~m}$ & 96 \\
\hline \multirow{2}{*}{$\mathrm{CHS}$} & CHS-E & $16^{\text {th }}$ July, 1991 & $160 \mathrm{~m}$ & 96 \\
\hline & CHS-W & $5^{\text {th }}$ Aug., 1991 & $140 \mathrm{~m}$ & 90 \\
\hline $\mathrm{CHV}$ & N/A & $13^{\text {th }}$ Aug., 1992 & $200 \mathrm{~m}$ & 98 \\
\hline
\end{tabular}

stands for a typical summer profile, two summer profiles dated July $14^{\text {th }}$ and located in ECS-E area (Fig. 1) were chosen from Fig. 2a and gave a new ECS-E sub-type summer polynomial curve shown in Fig. $2 b$.

Figure $2 c$ indicates two profiles obtained on July $14^{\text {th }}$ but located in the ECS-W area (Fig. 1 ), as well the other type of three similar profiles obtained on October $7^{\text {th }}$ in the same area. Acoustic velocities in the East China Sea Shelf posed a consistent trend in the thermocline zone where they were present in a fixed time period. Generally, bathymetric measurements obtained in the ECS area in July can be calibrated using the polynomial with the coefficients shown in Fig. 2a. However, in October it would transform into an ECS autumn sub-type, whose regressed polynomial would be defined by the coefficients denoted in Fig. 2c.

In the neighborhood of area ECS-E, an acoustic profile was collected in early September; Figure $2 b$ shows its unique curve compared with the typical ECS summer profile given in Fig. 2a. This phenomenon may indicate that the major form of acoustic profiles in the ECS area is seasonally rather than spatially dominated. However, almost all the profiles had a acoustic velocity of about $1515 \mathrm{~m} / \mathrm{s}$ at $80-\mathrm{m}$, sharing consistent bottom depth of the thermocline zones (or the pycnocline zone) in the period from July to October. 


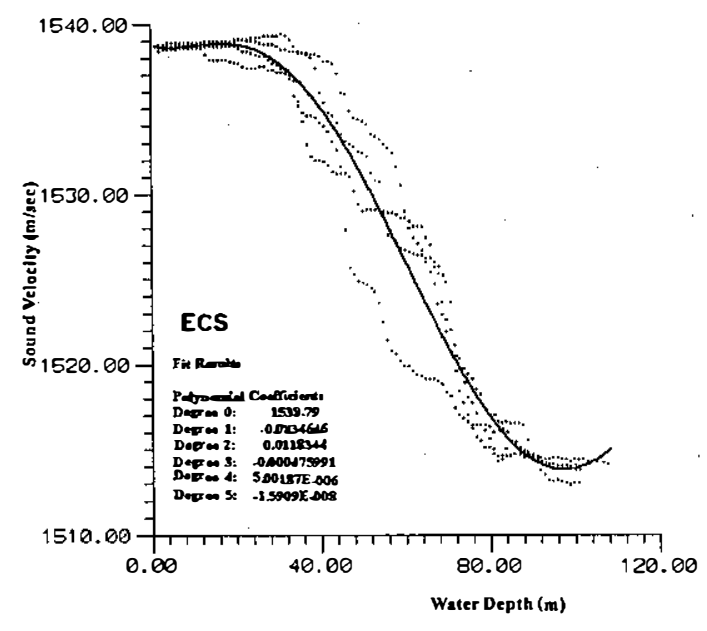

(a)

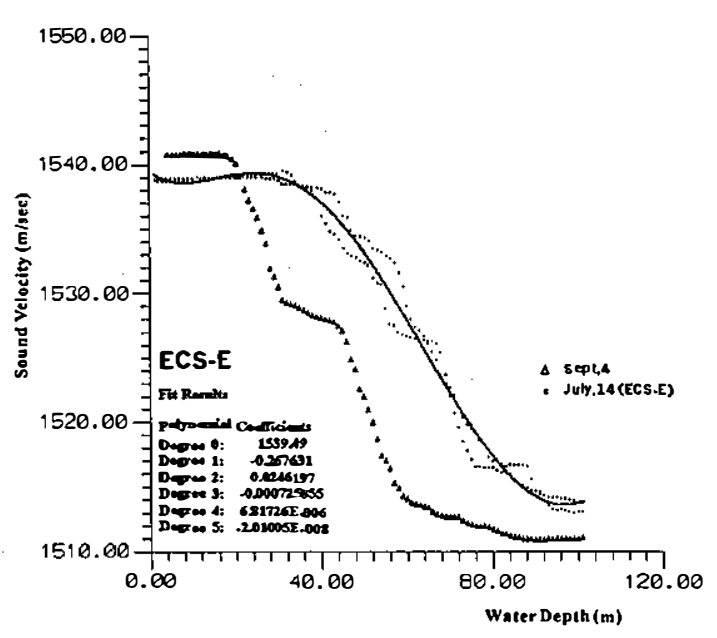

(b)

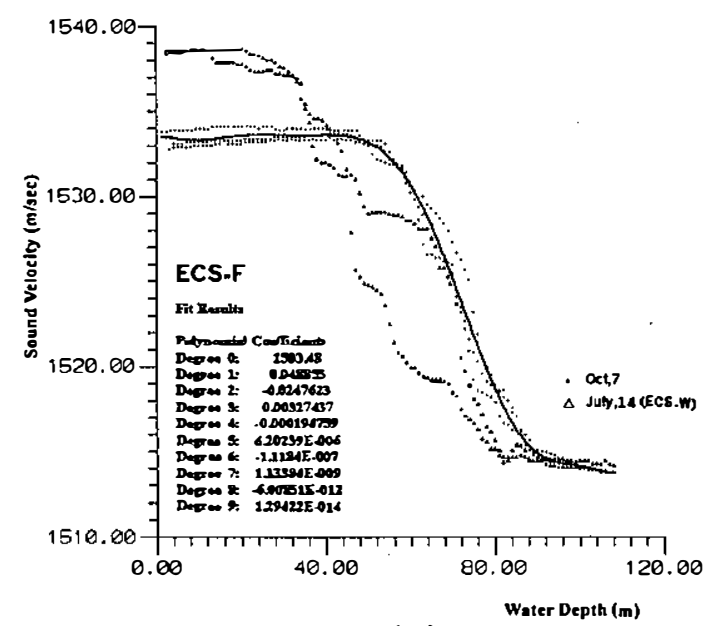

(c)

Fig. 2. Acoustic profiles of the ECS type. Figures 2a shows its typical summer $5^{\text {th }}$ order polynomial curve with a connected line, and its represented coefficient constants are denoted in the lower left-hand corner. Figure $2 b$ shows the ECS-E subtype polynomial (the connected curve) as well as the coefficients, two kinds of profiles were indicated by the dot and triangle lines, respectively, deployed on the date denoted on the diagram. Polynomial curve was determined by the July $14^{\text {th }}$ profiles measured in the ECS-E area. Figure 2c demonstrates the ECS autumn sub-type polynomial and its coefficients, the dot lines indicates the July $14^{\text {th }}$ profiles located in the ECS-W area. 


\subsection{MHC Type}

Two typical acoustic profiles measured in summer season belong to the Mien-Hua Canyon type. The chosen profiles were located inside the territory of the Mien-Hua Canyon in the vicinity of the continental shelf break, the shallower one is in the area of the Tunghai Shelf Fault (Song et al. 1997) and the other one is located above the southern bank of the canyon. A $9^{\text {th }}$ order polynomial curve denoted in Fig. 3a stands for a fitted profile in the canyon region within 360-m depth limit in summer season (Table 1).

Compared with the ECS summer profiles, the MHC polynomial curve has a very thin or merely identified mixed layer near the water surface (Fig. 3b). In addition, the trace of the MHC profiles is in-between the summer (Fig. 3b) and autumn type (Fig. 3c) of the ECS-E profiles as demonstrated in Fig. $2 \mathrm{~b}$. They were located in the neighborhood but to the north and on the shelf region.

\subsection{TEM Type}

This type of acoustic profile is placed once across the northern bank of upstream portion of the Mien-Hua Canyon, thus they are situated in the shelf region that bears a rather rough seafloor, inside the southern territory of the East China Sea Shelf. In this area, the pattern of acoustic velocity is not strictly similar to the ECS type or to the MHC type (Fig. 4). We then call it a Transit profile between the ECS type and MHC type.

\section{(A) Summer type}

In summer, the trend of acoustic profiles shown as Fig. 5 and its $5^{\text {th }}$ order regressed polynomial was given. These profiles were obtained within 2 NM by 2 NM area (NM stands for nautical mile, hereinafter) in the period from $1^{\text {st }}$ to $5^{\text {th }}$ of August 1990 and 1991. Their pattern is quite unique among the profiles such that its percentage of the least-square residuals about regression mean soon reaches $97 \%$.

Within the area, some scattering acoustic profiles were extracted and combined as a group shown in Fig. 6a (TEM-A; for TEM-Anomaly). Its regression output naturally gives lower 93\% residuals even at higher order. When they were put together in a plot (Fig. 6b), the TEM acoustic profiles almost lay on the top of those TEM-A profiles, relatively. Eventually, a typical TEM profile or regressed curve has a gentler velocity declined rate in the thermocline zone than that of the TEM-A profile.

Two acoustic profiles belonging to the ECS summer type of situated just to the north of the TEM profiles were put in the Fig. 5 for comparison (Fig. 7). Their patterns show some similarity; however, regressed curve of the TEM profiles displays a slightly steeper decline rate in the thermocline zone than that of the ECS profiles. This might be partially due to its smaller surface velocity.

It was shown that during summer the most steep velocity decline rate was found in the MHC profiles, and the ECS profiles instead gave a more gentle rate in the thermocline zone (Fig. 4). Together with the results shown in Figs. 6 and 7, this indicates that out the decline rate in the thermocline zone had the trend been decreasing northward, in sequence from the MHC, 


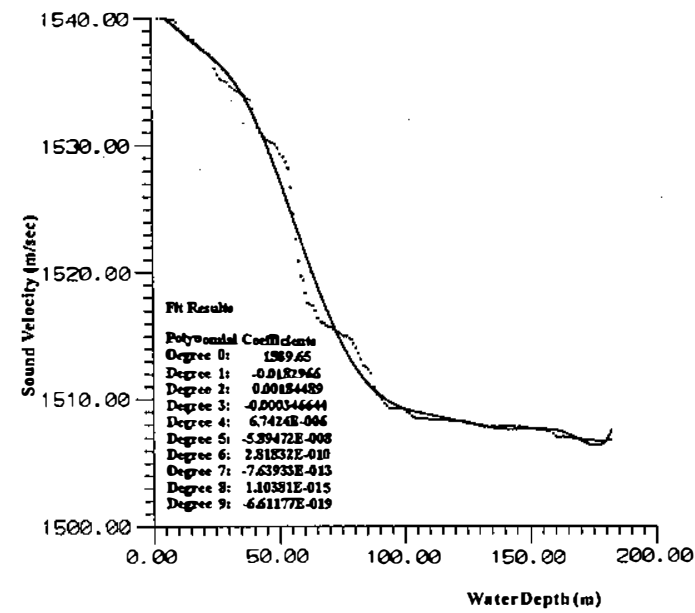

(a)

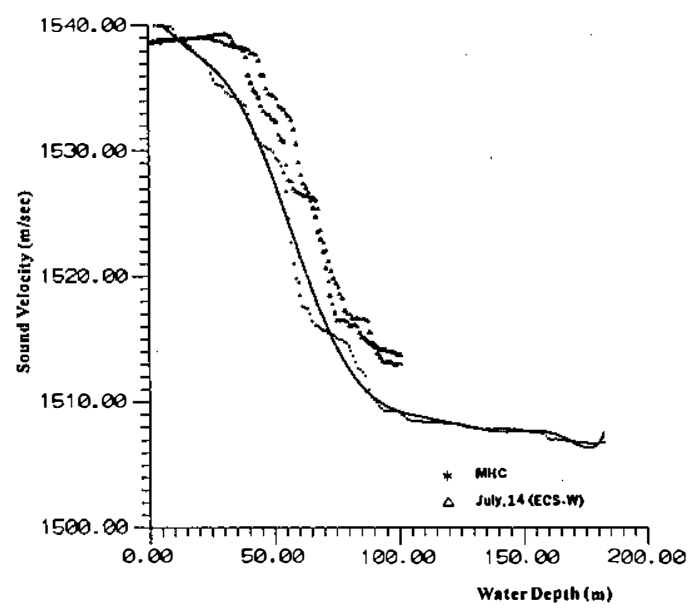

(b)

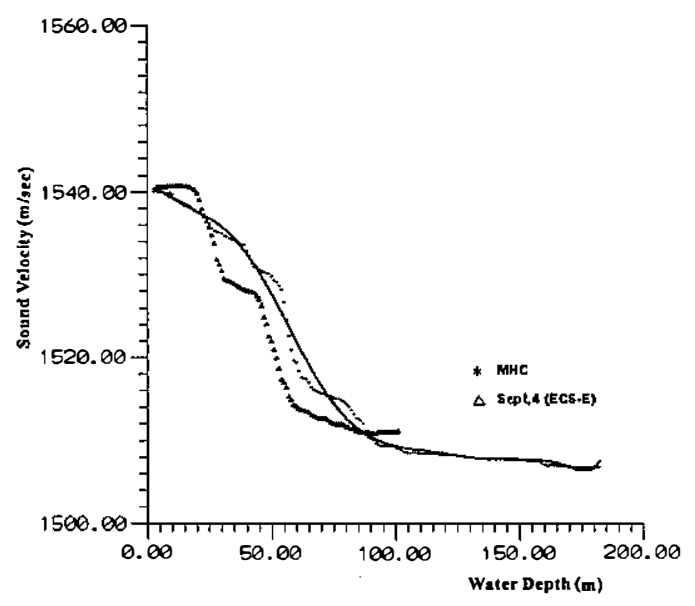

(c)

Fig. 3. Acoustic profiles of the MHC type. Figure 3a shows its $9^{\text {th }}$ order polynomial curve with a connected line, and its represented coefficient constants are denoted in the lower left-hand corner. Figures $3 b$, c show the comparison between the trace of the MHC profiles with the ECS-E summer and autumn profiles, respectively.

the TEM and toward the ECS. The implies that physical properties of water mass, such as the temperature, salinity etc., in the Mien-Hua Canyon and in the East China Sea Shelf had to be different and could be affecting each other. The TEM-A water column might include (or be mixed with) more Canyon water than that of the TEM typical type such that it could pose a steeper decline rate. 


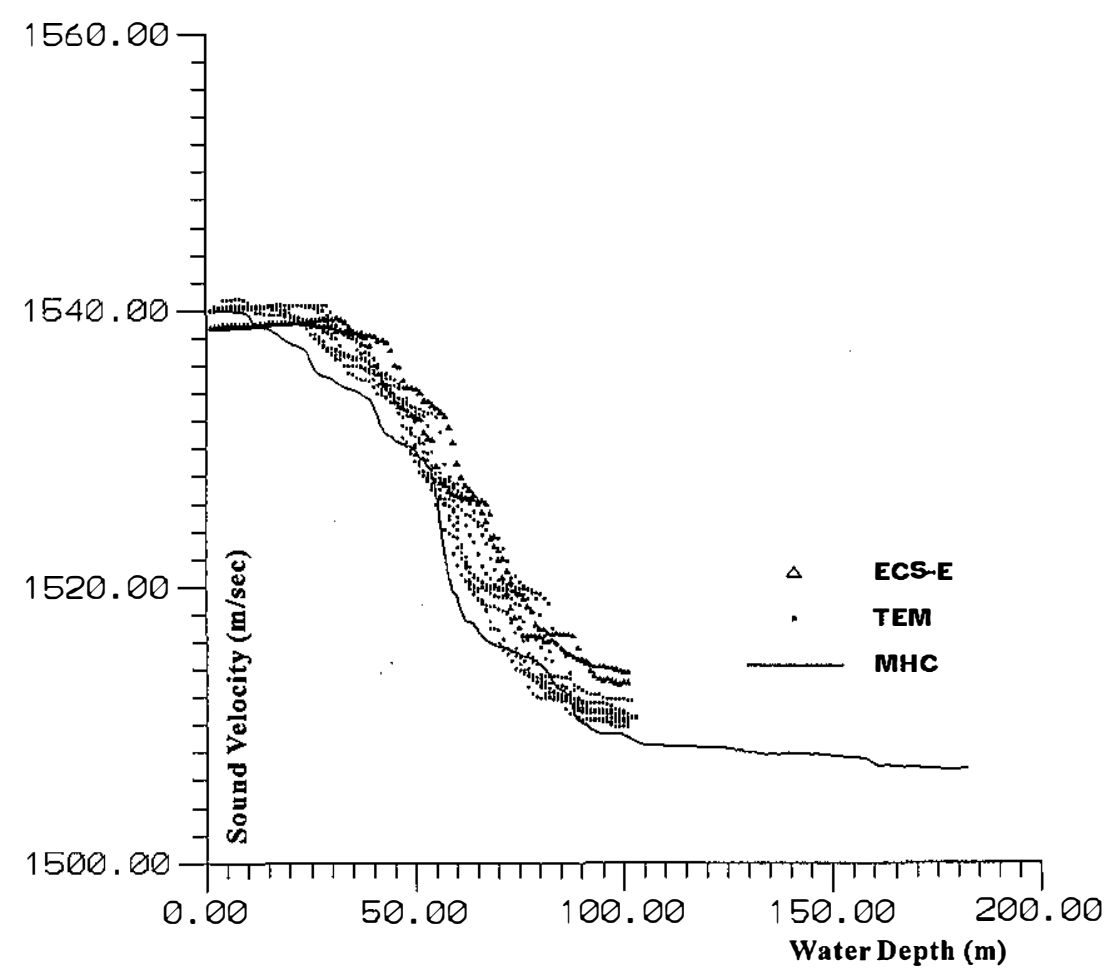

Fig. 4. Comparison plots among the acoustic profiles situated in the regions of the East China Sea Shelf (the ECS-E), the Mien-Hua Canyon (the MHC) and their transit territories (the TEM), respectively. Represented symbols to the profiles are denoted in the upper right-hand corner of diagram.

\section{(B) Autumn type}

In October, some acoustic profiles were obtained in the shelf area about $20 \mathrm{~km}$ west of the TEM area and north by the Mien-Hua Canyon (Fig. 1). Together with observed acoustic profiles, a $9^{\text {th }}$ order regressed polynomial is denoted and plotted in Fig. 8a. We call it the TEM$\mathrm{F}$ type, in which the capital "F" stands for fall season. Compared with the TEM profiles (Figs. $8 \mathrm{~b}, \mathrm{c}$ ), it has a narrower velocity band ranging from a surface velocity of about $1538 \mathrm{~m} / \mathrm{s}$ in a 30- $\mathrm{m}$ thick mixed layer, then decreasing in the thermocline zone to about $1512 \mathrm{~m} / \mathrm{s}$. In addition, the TEM-F profiles show a slower velocity in the surface layer (or the mixed layer) and a shallower depth to the bottom of thermocline zone, imply this area had been affected by colder surface water during the autumn season.

Eventually, autumn profiles of the ECS type (Fig. 2c) present a narrowest velocity band in thermocline zone from about $1534 \mathrm{~m} / \mathrm{s}$ on the top, decreasing to about $1514 \mathrm{~m} / \mathrm{s}$ reaching the bottom. However, it bears a thicker mixed layer extending to $52 \mathrm{~m}$ deep. Apparently, the pattern of the TEM-F profiles looks like a lifted (brings it to water surface by $22 \mathrm{~m}$ ) and pulled-apart (extended in its velocity scale) ECS autumn profile (Fig. 8d). This implies the 


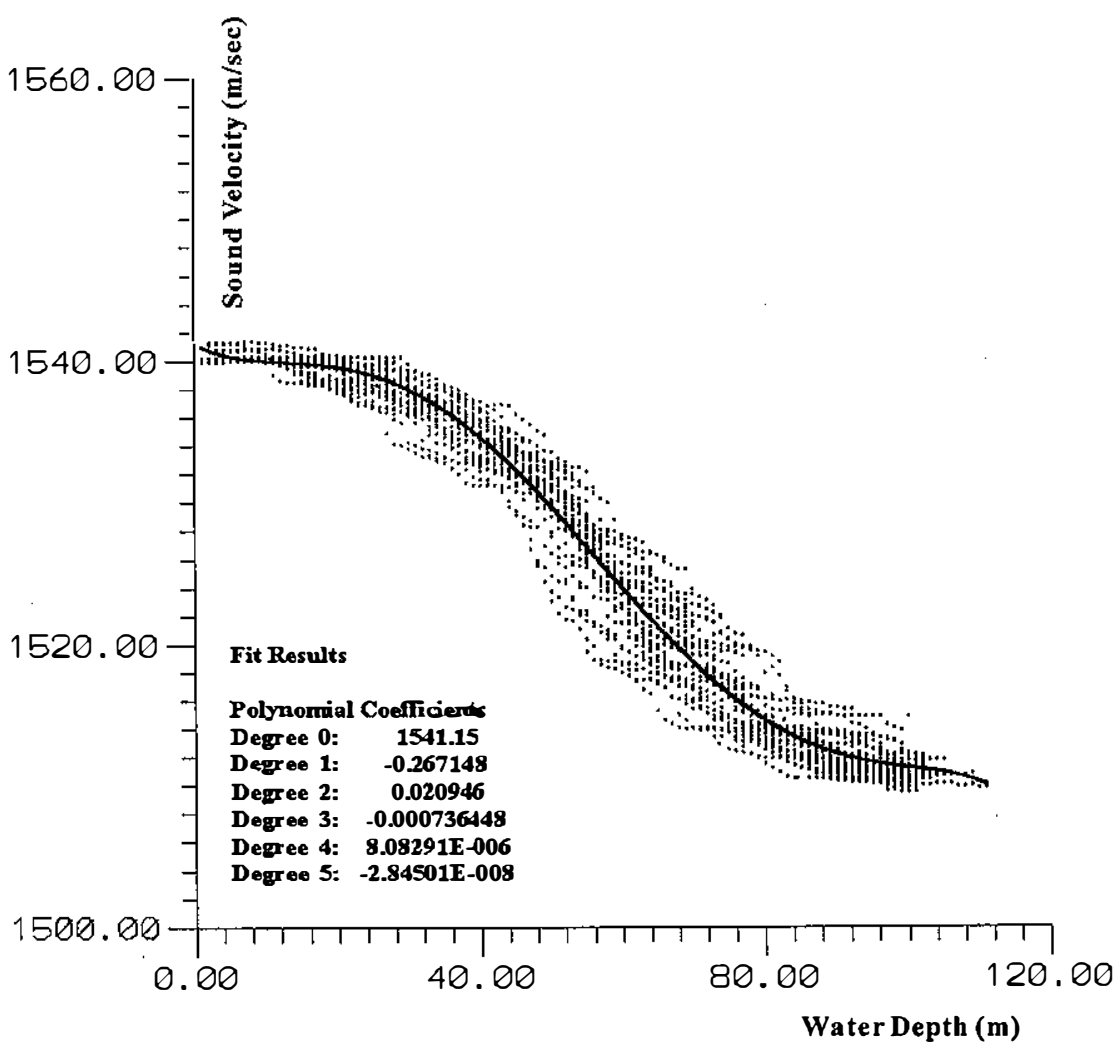

Fig. 5. Acoustic profiles of the TEM type. A $5^{\text {th }}$ order polynomial curve with a connected line is shown, and its represented coefficient constants are denoted in the lower left-hand corner.

influence of much colder surface water in the north of the ECS area away from the territory of the Mien-Hua Canyon. Thus the shape of TEM-F profiles reflects the temperature dominant characteristic in that area.

\subsection{CHS Type}

Figure 9 demonstrates two acoustic profiles in the outer portion of the CHilung Shelf (the CHS-E shown in Fig. 1). The location is in equal distance of about 10 kilometers to the nearest bound of the Mien-Hua Canyon, the Chilung Valley and the edge of the Chilung Shelf, respectively. The pattern of acoustic profiles shown in Fig. 9 give variant looks compared with each other. Even in the CHS-E profiles, although they were only about $1 \mathrm{NM}$ apart in the distance, they demonstrated only an identical 25 -m thick mixed layer but trended apart in the deep.

A $6^{\text {th }}$ order of polynomial curve for the CHS-E profiles was obtained by the least-square regression, as shown in the Fig. 10a. Their looks both had step-like trace and stood separately in the respective thermocline zone. Figure $10 \mathrm{~b}$ shows the CHS-E profiles and puts them to- 


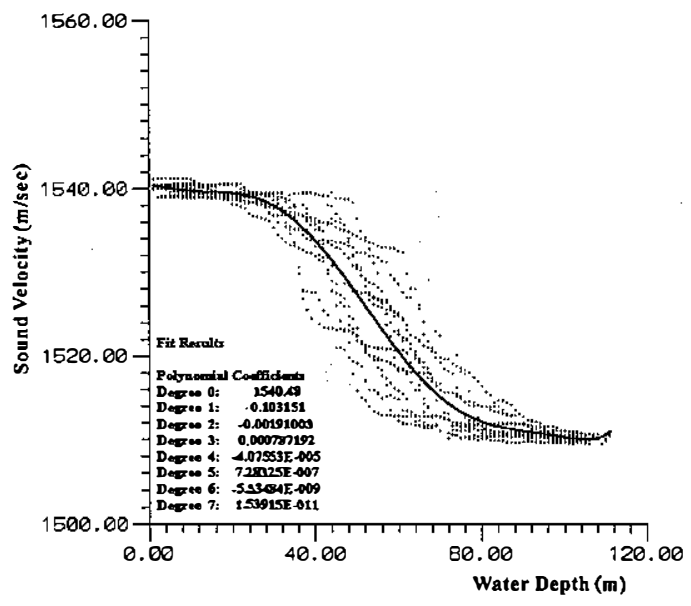

(a)

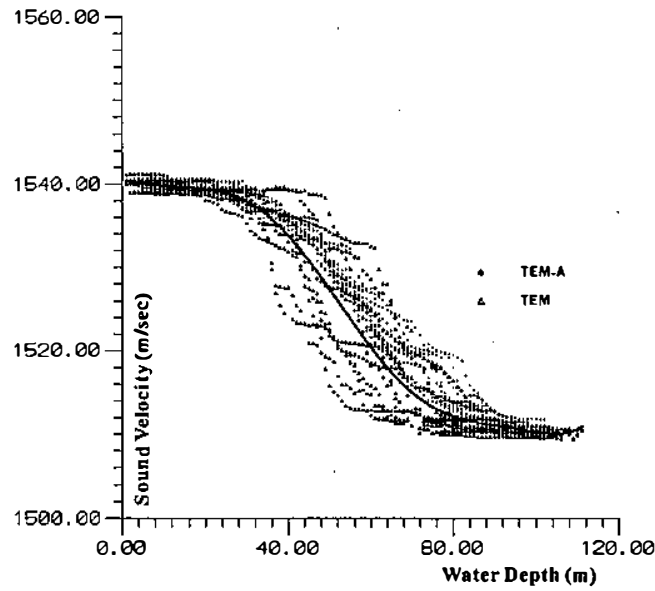

(b)

Fig. 6. Acoustic profiles of the TEM-A type. A $7^{\text {th }}$ order polynomial curve with a connected line is shown in (a) also (b), and its represented coefficient constants are denoted in the lower left corner of Fig. 6a. Measurements defined by "triangles" symbol defined by TEM denoted in the right-hand upper corner are belonged to the content of the acoustic profiles shown in Fig. 5 in which TEM-A profiles had been removed.

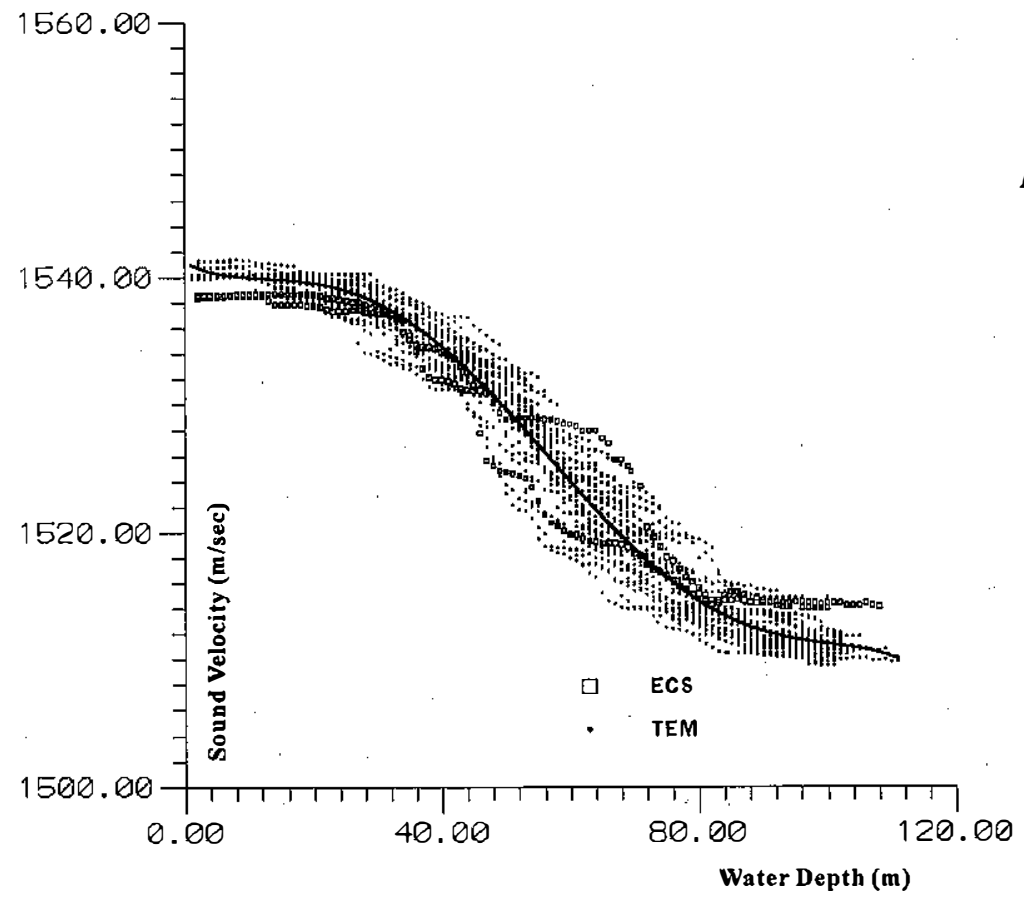

Fig. 7. Acoustic profiles of the TEM type compared with the ECS profiles. Two acoustic profiles belonging to the ECS summer type located in the ECS-W area are indicated by empty squares. The connected line is the same TEM polynomial curve shown in Fig. 6a. 


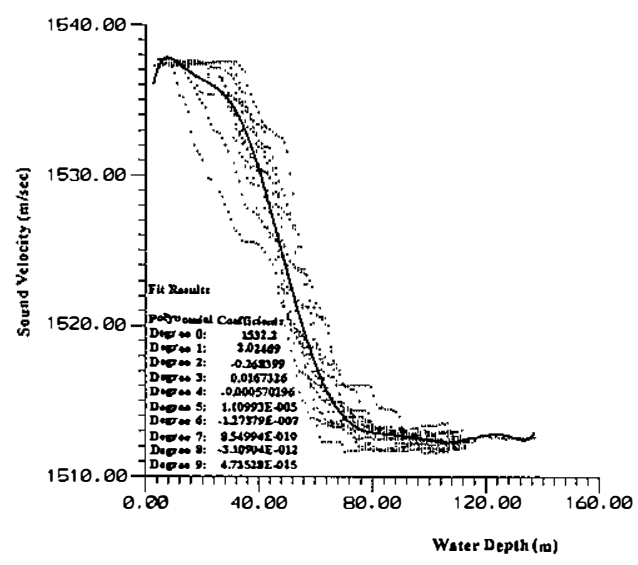

(a)

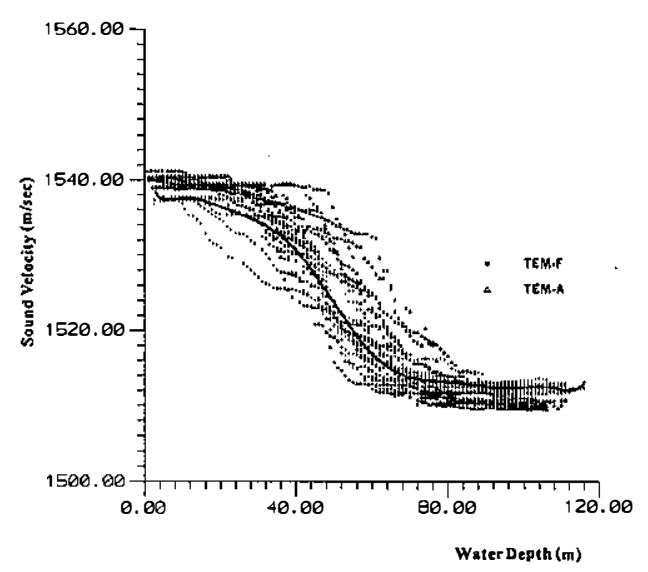

(c)

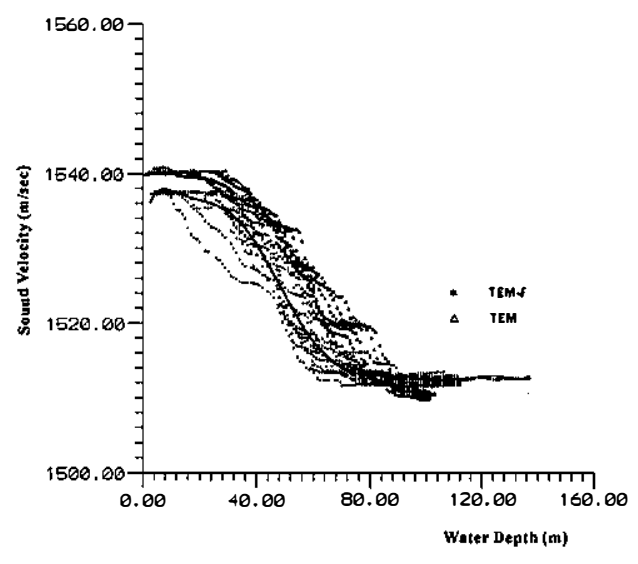

(b)

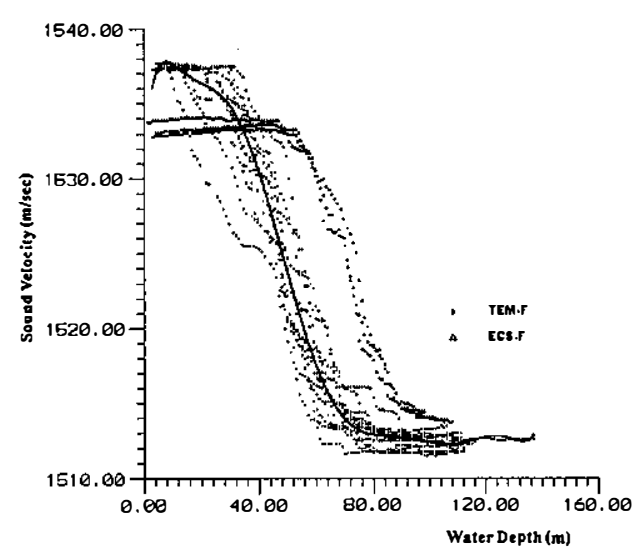

(d)

Fig. 8. Acoustic profiles of the TEM-F type shown in (a), and its comparisons with other types of acoustic profiles. In (b) with the typical TEM profiles; (c) with the TEM-A profiles; (d) with the ECS-F profiles. Its $9^{\text {th }}$ order polynomial curve is shown by connected line denoted in the each drawing, respectively. Represented coefficient constants are denoted in the lower left-hand corner of Fig. 8a.

gether with those acoustic profiles deployed in the western region of the Chilung Shelf for comparison. Although they shared almost a constant surface velocity in the mixed layer, and kept the thermocline bottom depth at around $80 \mathrm{~m}$, velocity decline rates showed variance in the profiles (Fig. 10b). A steeper rate such that a smaller acoustic velocity was observed in the deep in the western Chilung Shelf.

The western profiles shown in Fig. 10b belong to part of the group (called the CHS-W) 


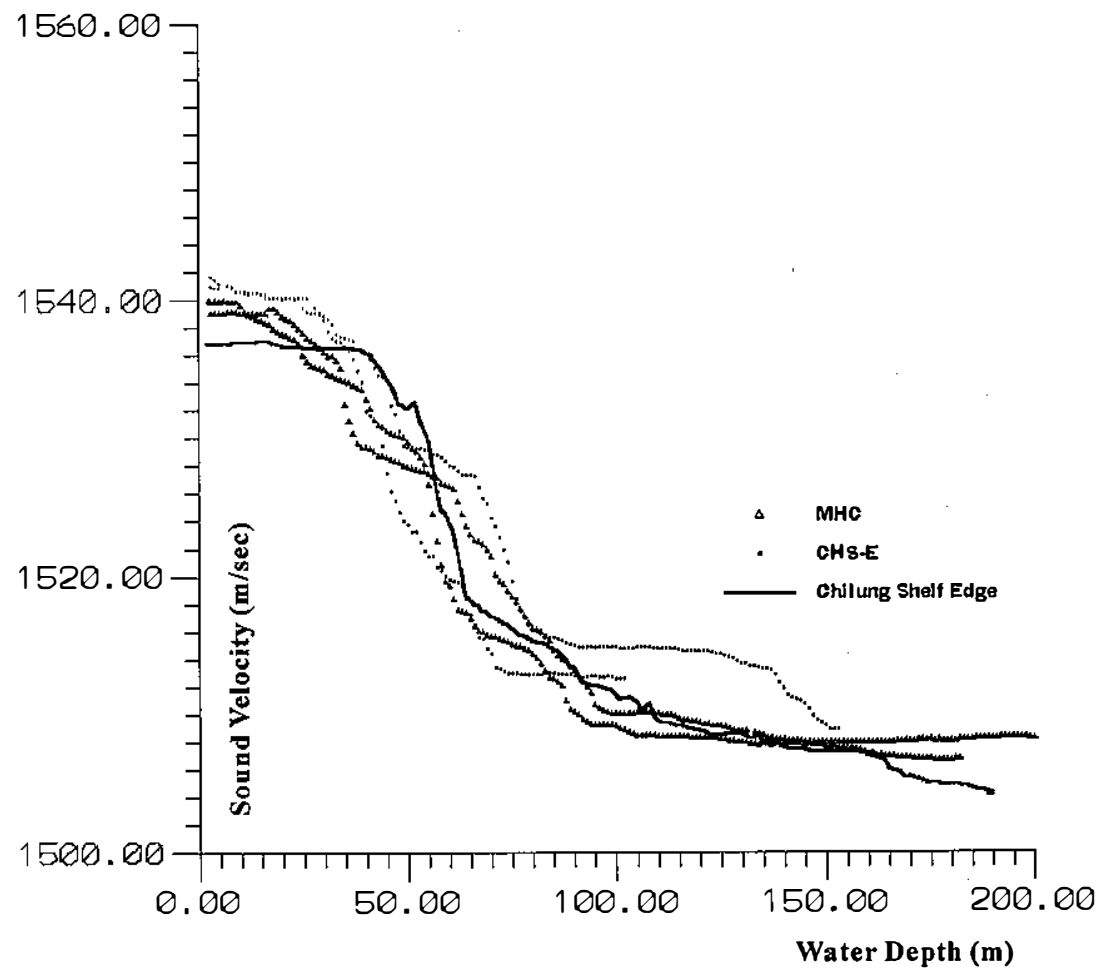

Fig. 9. Comparison plots among the acoustic profiles that situated in the Chilung Shelf and the Mien-Hua Canyon regions. The curved connected line denotes the acoustic profile in the location almost at the edge of the Chilung Shelf (Its location name denoted as Edge in Fig. 1). Small dots' profiles make the CHS-E type of acoustic profile shown in Fig. 10a.

observed in the area situated in the western Chilung Shelf (Song et al. 1997). This group of acoustic profiles was collected within a $2 \mathrm{NM}$ by $2 \mathrm{NM}$ area situated $10 \mathrm{NM}$ north of the Chilung City in August $5^{\text {th }}$ (Fig. 1, Table1). The pattern of profiles and the fitted polynomial are shown in Fig. 11.

Figure 11 shows the acoustic profiles posing the shape with consistent pattern and with about identical thickness of the thermocline zone, however the top of thermocline zone could be at depths ranging at $35 \mathrm{~m}$ from $20-\mathrm{m}$ to $55-\mathrm{m}$. In this case, the maximum percentage of regression residuals is low at $90 \%$. This range would become narrower to about $28 \mathrm{~m}$ (Fig. 12) after those profiles situated merely in a much smaller area of a $1 \mathrm{NM}$ by $1 \mathrm{NM}$ right-hand lower corner sub-area in the CHS-W area (Fig. 1). The phenomenon could be enhanced for those profiles located along in a longitudinal line of this sub-area. The acoustic profiles collected in the stations S1 and S4 then had a much narrower range to $20 \mathrm{~m}$ with the top of thermocline zone at depths from 32-m to 52-m (Fig. 13a). Furthermore, to the west where two CTD stations occupied another longitudinal line (numbered S2 and S7 shown in Fig. 1), their profiles were plotted as a group in Fig. 13b; the traces become stuck together, such that its 


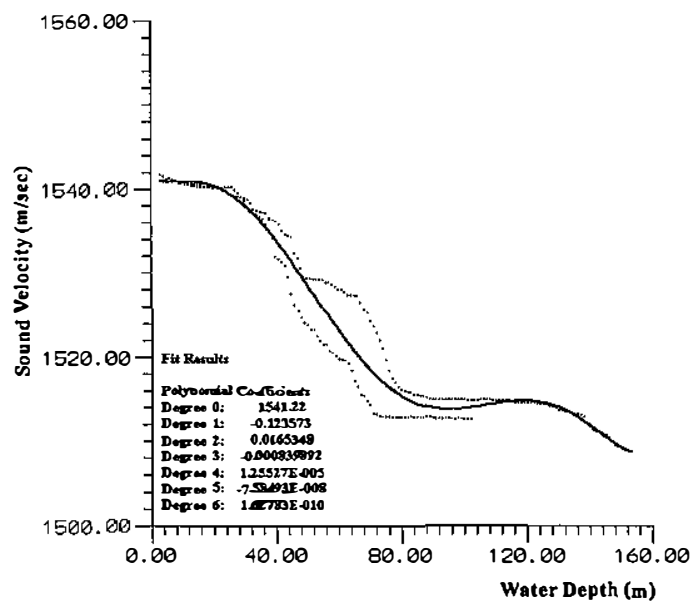

(a)

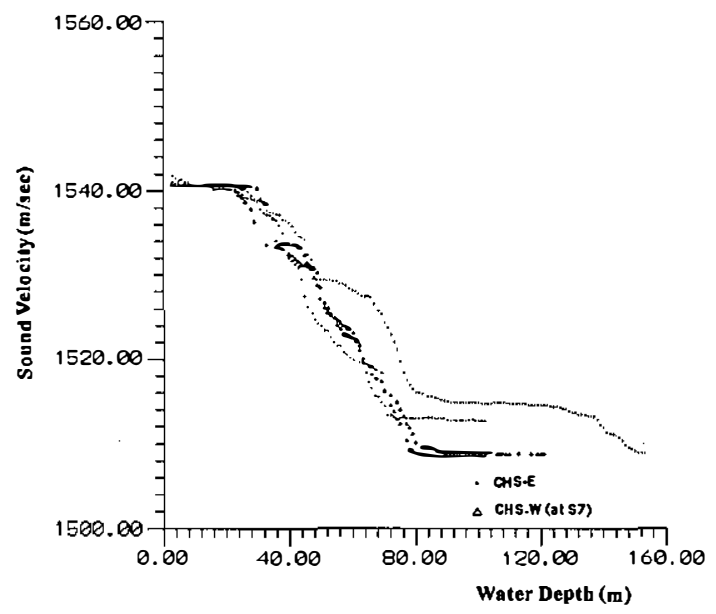

(b)

Fig. 10. Acoustic profiles of the CHS-E type. Figure 10a shows a $6^{\text {th }}$ order polynomial curve with a connected line, and its represented coefficient constants are denoted in the lower left-hand corner. Figure 10b shows its comparison with the profiles (denoted by triangles) at Station 7 (or S7 shown in Fig. 1) in the CHS-W area.

residual about regression mean reached $99 \%$ quit easily. This might imply that physical properties of water columns in this area were mainly dominated by a dynamic with an east-west orientated behavior in summer time.

\subsection{CHV Type}

There were only two profiles included to obtain the regressed polynomial for the type shown in the CHilung Valley. The regression coefficients are denoted in Fig. 14a. The profiles show step-like trace, which is similar with those shown in the Chilung Shelf area, especially in the CHS-E area. However, they look different in Fig. 14b, the water seems to be warmer in the Chilung Valley.

\section{DISCUSSIONS}

Table 2 lists 40 observed values of bathymetric measurements with a preset acoustic mean velocity $1500 \mathrm{~m} / \mathrm{s}$ (Song and Chen 1994). These measurements were conducted in the ECS area (Fig. 1) during summer in 1993. Therefore, according to the study, these observed depths should be corrected by using the ECS type polynomial defined in Fig. 2a. Results are shown in the $4^{\text {th }}$ column (ECS-S, $-S$ stands for summer type) listed in Table 2 . In the depth range between $105-120 \mathrm{~m}$ for these 40 samples, the values of acoustic required correction are constant at $+2.0 \pm 0.1(+2.1$ at $120 \mathrm{~m}$ to +1.94 at $105 \mathrm{~m})$. 


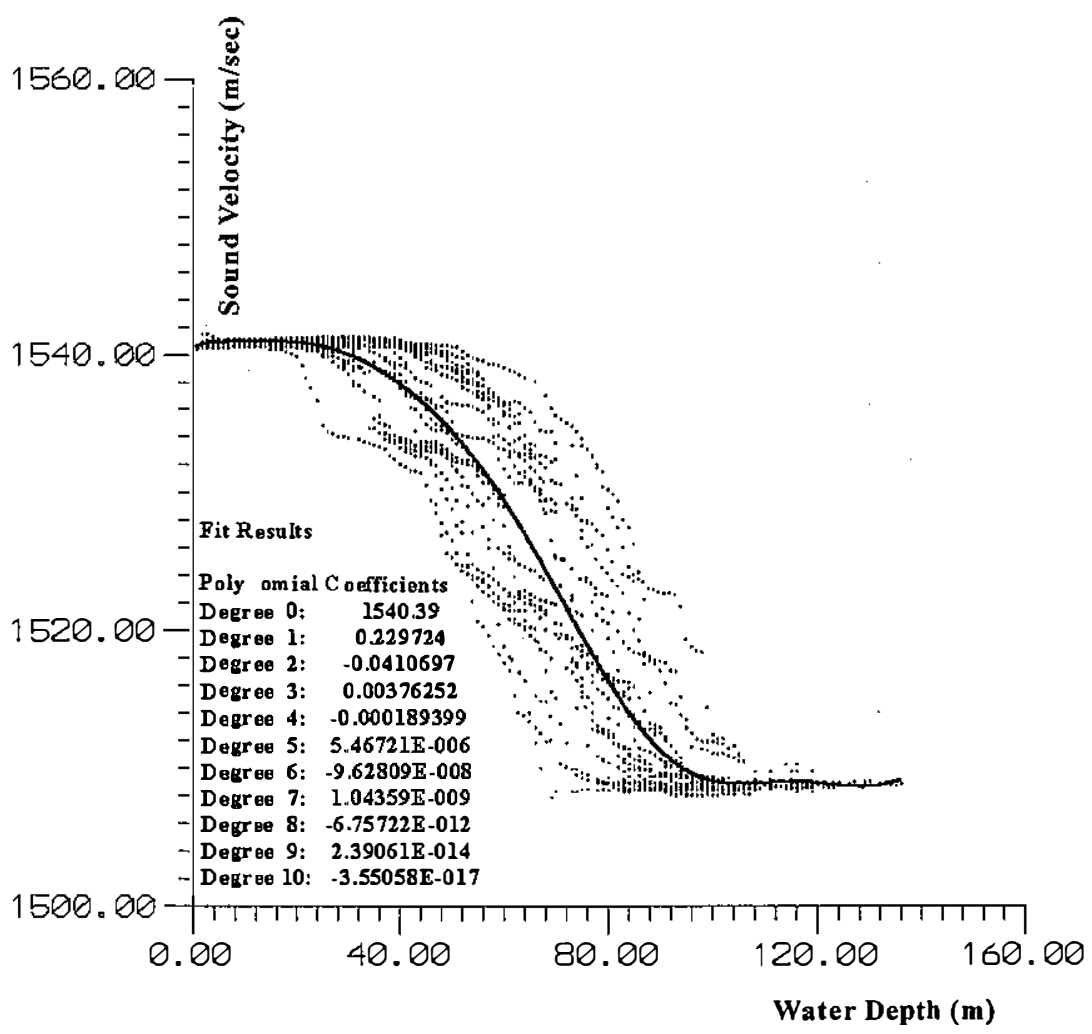

Fig. 11. Joint acoustic profiles of the CHS-W type. A $10^{\text {th }}$ order polynomial curve with a connected line is shown, and its represented coefficient constants are denoted in the lower left-hand corner. These profiles put together all the measurements collected in a wider region compared with those shown in Figs. 12 and 13.

However, different ECS types of polynomial were applied, such as ECS-E and ECS-F (for autumn type), their results show less variation with that corrected by the ECS summer type (Fig. 15). Table 2 indicates their variation is within $\pm 0.1 \mathrm{~m}$, in which autumn type gives different trend and wider range of variation $(+0.1$ at $120 \mathrm{~m}$ and -0.04 at $150 \mathrm{~m})$. According to 106 samples shown in Fig. 15, except showing that the ESC-S type is good in calibrating the bathymetric measurements collected in the region of the East China Sea Shelf, the correction result applied by ECS-E, even by ECS-F, can also give bathymetric precision within $0.1 \%$.

This study thus suggests that there is almost $2 \%$ of bathymetric error when using a 1500 $\mathrm{m} / \mathrm{s}$ preset sounding velocity without further doing proper acoustic calibration in the offshore area of northern Taiwan. According the calibration results given by regression polynomials shown in Figs. 2 to 14, Table 3 shows expected mean sounding velocities for each defining area in which the represented value can be a suitable preset velocity sounding off northern Taiwan. 


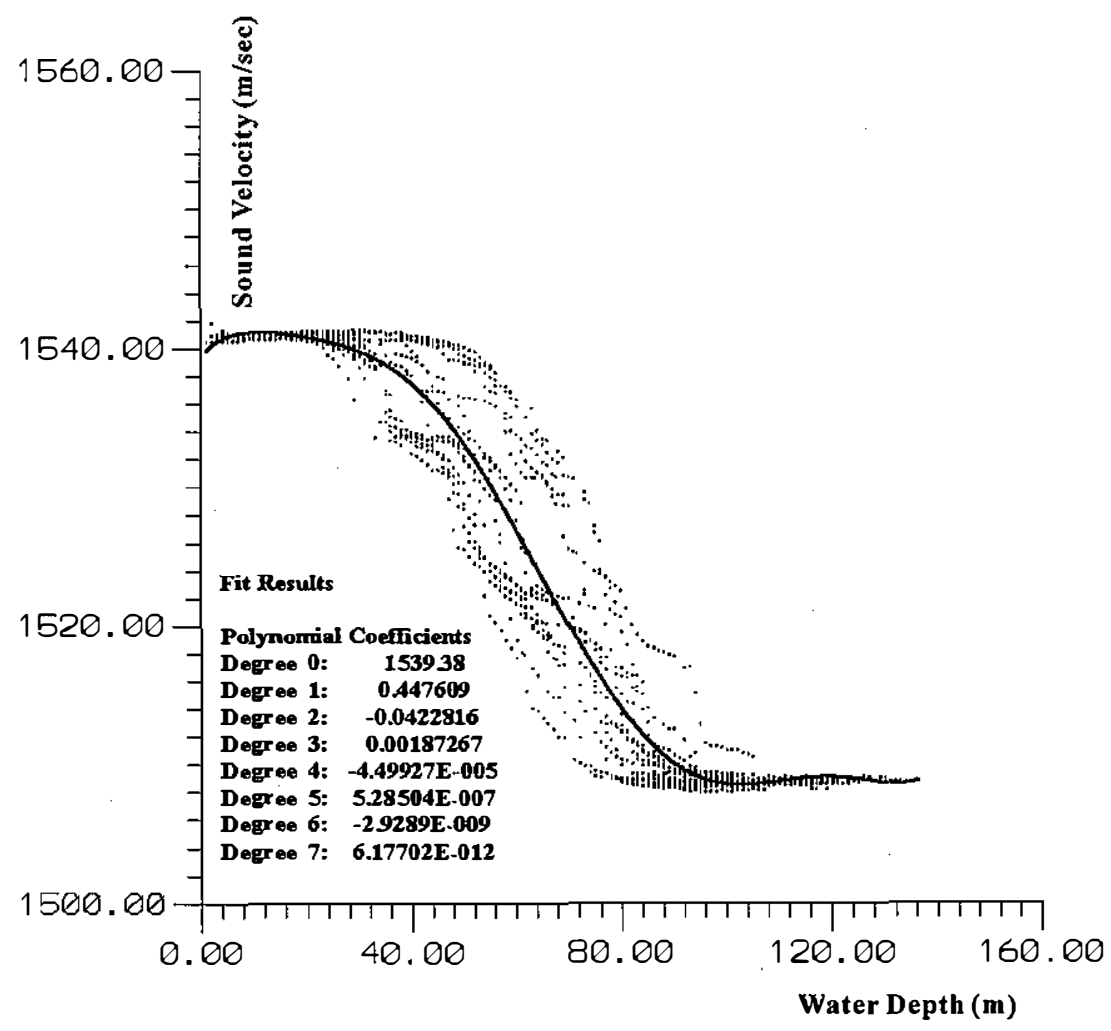

Fig. 12. Partial acoustic profiles of the CHS-W type. A $7^{\text {th }}$ order polynomial curve with a connected line is shown, and its represented coefficient constants are denoted in the lower left-hand corner. These profiles were all located in the right-hand lower corner of the CHS-W area denoted by an inset shown in Fig. 1.

Expected mean velocity would change if the depths to the seafloor were variant, this is due to acoustic profile being a curve down to the deep. However, there is an advantage that the sea floor mostly keeps within a limited range of depths in the continental shelf, a narrower range of expected mean velocities can then be applied. For instance, in the East-China Sea Shelf or the ECS area of this study, the depths have been in the range mostly between $110 \mathrm{~m}$ to $125 \mathrm{~m}$ as shown in Table 2. Eventually, expected mean velocity ranges from $1525 \mathrm{~m} / \mathrm{s}$ to 1529 $\mathrm{m} / \mathrm{s}$ at most, referring to the listed values shown in the ECS and TEM Areas of Table 3. Under this circumstance, if $1527 \mathrm{~m} / \mathrm{s}$ is set for a sounding velocity, a sounding accuracy of less than $0.13 \%$ (or 2/1527) can be obtained in summer or autumn season.

Applied to the Chilung Shelf Area, even if it poses a rather rough seafloor and ranges between $140-220 \mathrm{~m}$, an expected mean velocity could be at $1523 \mathrm{~m} / \mathrm{s}$ of less than $0.2 \%$ accuracy, according to Table 3. In the canyon or the valley regions offshore northern Taiwan, the mean velocities will be lower due to colder water in the deep. If it is set at $1515 \mathrm{~m} / \mathrm{s}$, the accuracy is still good at $0.33 \%$ (or $5 / 1515$ ). 


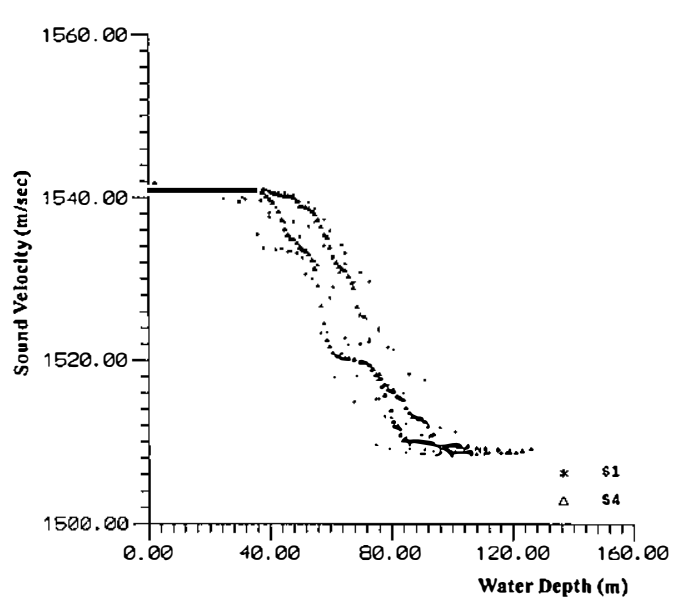

(a)

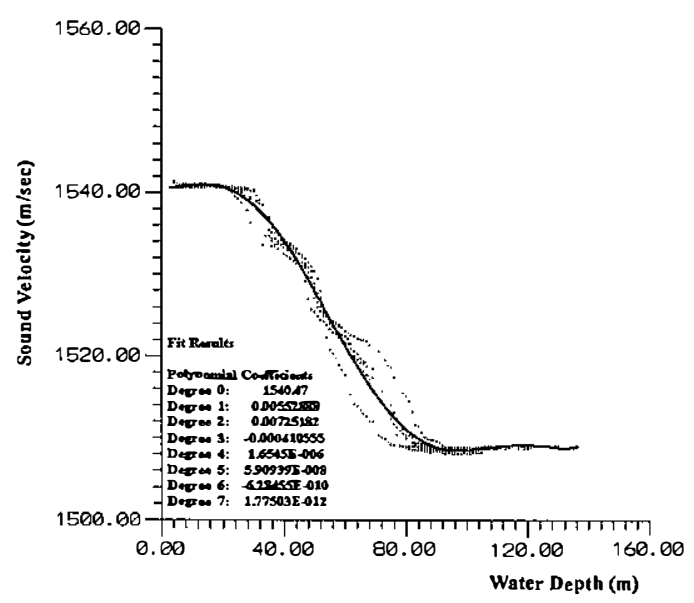

(b)

Fig. 13. Acoustic profiles that located along a longitudinal line in the CHS-W area. (a) is for those located at Stations 1 and 4. (b) is for those located at Stations 2 and 7 shown in Fig. 1. A $7^{\text {th }}$ order polynomial curve with a connected line is shown in (b), and its represented coefficient constants are denoted in the lower left-hand corner.

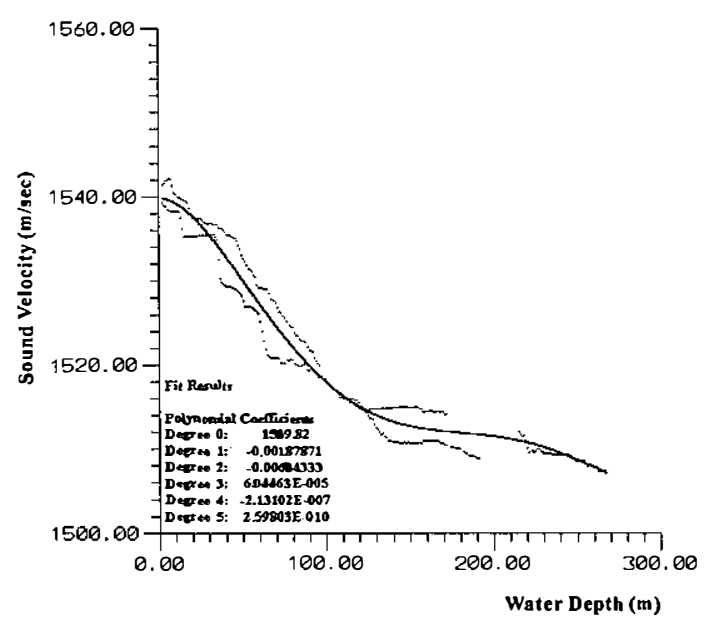

(a)

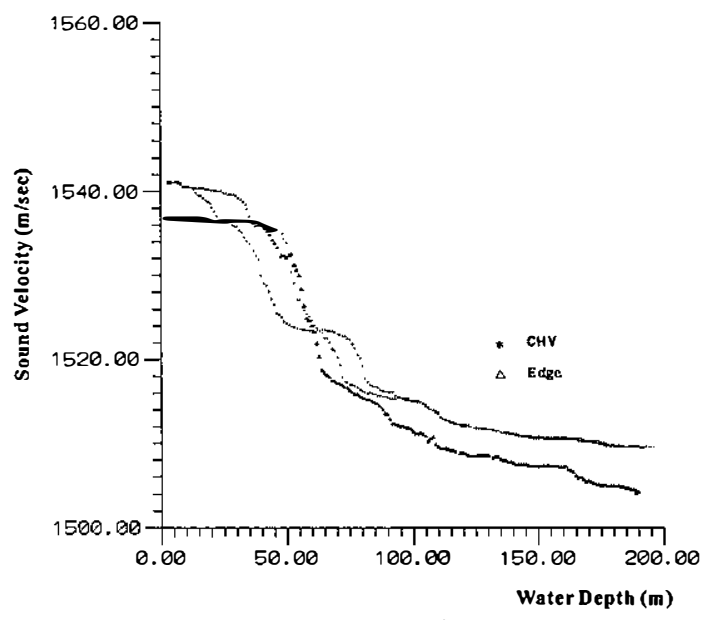

(b)

Fig. 14. Acoustic profiles of the CHV type. A $5^{\text {th }}$ order polynomial curve with a connected line is shown in (a), and its represented coefficient constants are denoted in the lower left corner. In (b), the Chilung Shelf break profile shown also in Fig. 9 named Edge is plotted for comparison. 
Table 2. Calibration results in the samples located in the ECS area. Observed Depths were obtained by a preset echo-sounding velocity at $1500 \mathrm{~m} / \mathrm{s}$. Tabulated values in columns 4,5 and 6 were derived from the calibration algorithm stated in this article using the regressed polynomials defined in Figs. 2a, b, c, respectively.

\begin{tabular}{|c|c|c|c|c|c|}
\hline E Longi tude & N Lat itude & $\begin{array}{l}\text { Observed } \\
\text { Depths }(m)\end{array}$ & $\begin{array}{c}\text { ECS Calibrated } \\
\text { Depths }(m)\end{array}$ & $\begin{array}{c}\text { ECS-E Calibrated } \\
\text { Depths (m) }\end{array}$ & $\begin{array}{c}\text { ECS-F Cal ibrated } \\
\text { Depths }(m)\end{array}$ \\
\hline 121.99977200 & 25.59170400 & 115.35 & 117.40 & 117.47 & 117.37 \\
\hline 121.99857800 & 25.59172700 & 113.97 & 116.00 & 116.07 & 115.97 \\
\hline 121.99736400 & 25.59174600 & 117.30 & 119.37 & 119.45 & 119.37 \\
\hline 121.99614600 & 25.59177900 & 119.07 & 121.16 & 121.24 & 121.21 \\
\hline 121.99492300 & 25.59181700 & 120.15 & 122.25 & 122.34 & 122.34 \\
\hline 121.99370500 & 25.59186200 & 118.80 & 120.89 & 120.97 & 120.92 \\
\hline 121.99251900 & 25.59202800 & 118.00 & 120.08 & 120.15 & 120.09 \\
\hline 121.99147600 & 25.59244600 & 117.47 & 119.54 & 119.62 & 119.55 \\
\hline 121.99064800 & 25.59307400 & 116.80 & 118.86 & 118.94 & 118.86 \\
\hline 121.99009800 & 25.59387200 & 115.95 & 118.00 & 118.08 & 117.99 \\
\hline 121.98982700 & 25.59473000 & 115.80 & 117.85 & 117.92 & 117.83 \\
\hline 121.98974100 & 25.59561600 & 117.87 & 119.95 & 120.02 & 119.96 \\
\hline 121.98976700 & 25.59651700 & 117.97 & 120.05 & 120.12 & 120.06 \\
\hline 121.98987100 & 25.59738600 & 117.45 & 119.52 & 119.60 & 119.53 \\
\hline 121.99003100 & 25.59824200 & 116.88 & 118.94 & 119.02 & 118.94 \\
\hline 121.99026300 & 25.59908400 & 115.75 & 117.80 & 117.87 & 117.78 \\
\hline 121.99050400 & 25.59993300 & 115.97 & 118.02 & 118.10 & 118.01 \\
\hline 121.99991700 & 25.57587100 & 112.28 & 114.29 & 114.36 & 114.25 \\
\hline 121.99894400 & 25.57580600 & 111.06 & 113.06 & 113.13 & 113.02 \\
\hline 121.99799300 & 25.57582900 & 110.33 & 112.32 & 112.39 & 112.28 \\
\hline 121.99702300 & 25.57584600 & 108.55 & 110.52 & 110.59 & 110.49 \\
\hline 121.99605400 & 25.57583400 & 106.15 & 108.10 & 108.16 & 108.06 \\
\hline 121.99511000 & 25.57583200 & 105.08 & 107.02 & 107.08 & 106.98 \\
\hline 121.99411600 & 25.57582300 & 109.34 & 111.32 & 111.39 & 111.28 \\
\hline 121.99319000 & 25.57586900 & 114.15 & 116.18 & 116.25 & 116.15 \\
\hline 121.99224000 & 25.57584400 & 113.35 & 115.37 & 115.44 & 115.34 \\
\hline 121.99127100 & 25.57582800 & 114.15 & 116.18 & 116.25 & $116: 15$ \\
\hline 121.99034000 & 25.57570600 & 115.35 & 117.40 & 117.47 & 117.37 \\
\hline 121.98951200 & 25.57531300 & 114.92 & 116.96 & 117.03 & 116.94 \\
\hline 121.98878800 & 25.57477800 & 114.80 & 116.84 & 116.91 & 116.81 \\
\hline 121.98827700 & 25.57409500 & 114.55 & 116.59 & 116.66 & 116.56 \\
\hline 121.98784600 & 25.57333900 & 114.28 & 116.31 & 116.38 & 116.28 \\
\hline 121.98742800 & 25.57256300 & 114.03 & 116.06 & 116.13 & 116.03 \\
\hline 121.98702400 & 25.57179600 & 114.65 & 116.69 & 116.76 & 116.66 \\
\hline 121.98661300 & 25.57103600 & 115.11 & 117.15 & 117.23 & 117.13 \\
\hline 121.98621600 & 25.57027400 & 114.40 & 116.44 & 116.51 & 116.41 \\
\hline 121.98585400 & 25.56949300 & 113.56 & 115.59 & 115.66 & 115.55 \\
\hline 121.98560900 & 25.56866800 & 113.20 & 115.22 & 115.29 & 115.19 \\
\hline 121.98538600 & 25.56785400 & 111.04 & 113.04 & 113.11 & 113.00 \\
\hline 121.98517400 & 25.56702500 & 112.64 & 114.66 & 114.72 & 114.62 \\
\hline
\end{tabular}



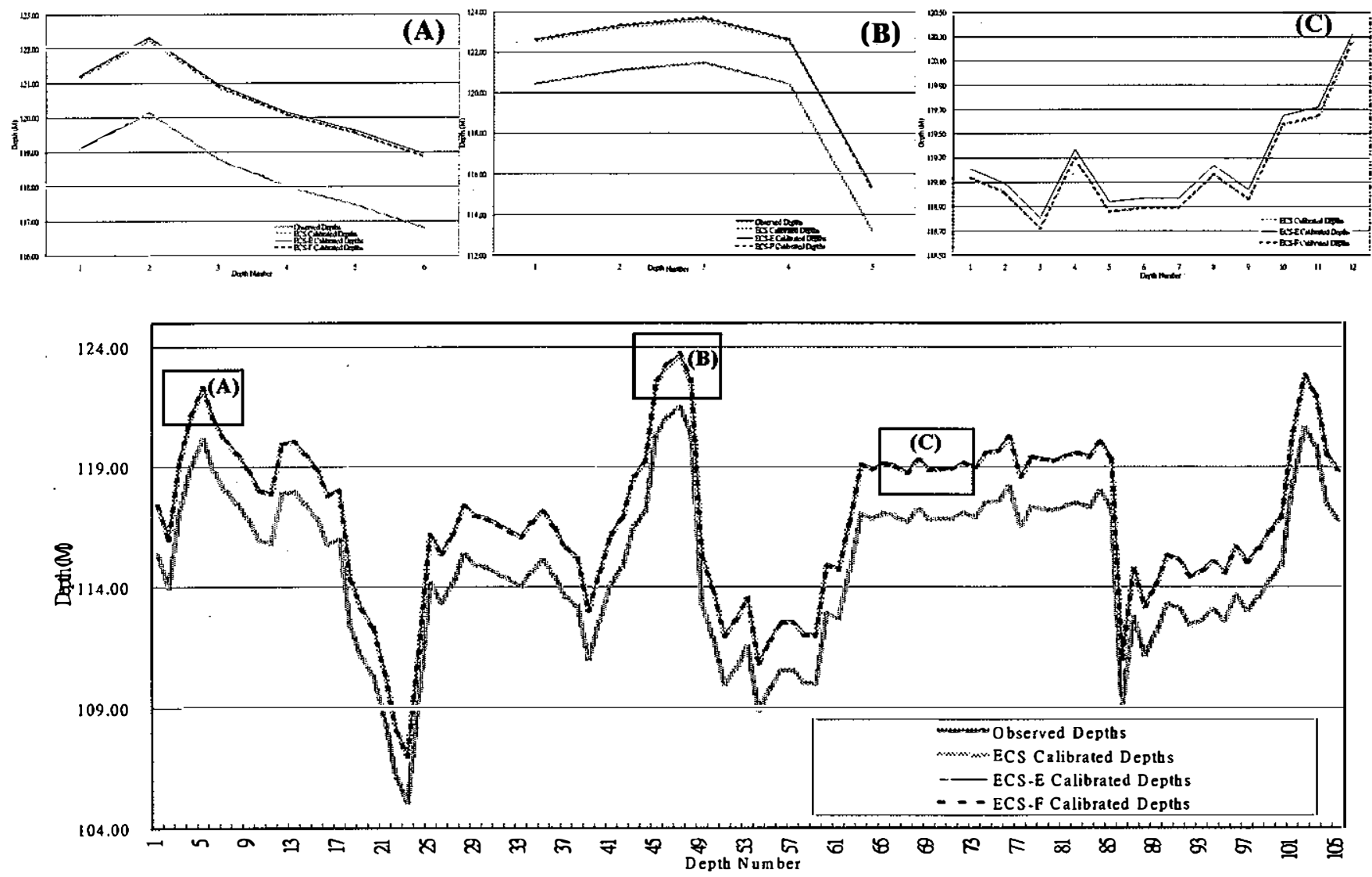

Fig. 15. Calibration outputs to the 106 observed depths that were collected in the ECS-W area of the East China Sea Shelf using $1500 \mathrm{~m} / \mathrm{s}$ preset acoustic velocity. Locations of first 40 samples are listed in Table 2. These outputs were plotted following the sequence of depth samples to compare the traces of calibrated depth profile with those observed depth values. Three different types of regression coefficients were applied for calibration, and each was done by the type belonged to the ECS, the ECS-E and ECS-F, respectively, denoted in Fig. 2. Results show less variation among these types and were discussed in the text. 
Table 3. Expected mean velocities in the defining areas off northern Taiwan. At first, the value of travelling time of an acoustic echo can be computed from a single observed depth divided by a preset velocity. The expected mean velocity then can be estimated by dividing an acoustic correction depth that was derived from the calibration algorithm using the regressed polynomials defined in that specified area. Depths of territories in the $3^{\text {td }}$ column simply indicate the lower and upper bounds of observed depth in the areas (except for that 90-meter in the TEM type). However, the lower bound (or deeper value) estimations were usually limited and replaced by the Depth Limitation values shown in Table 2.

\begin{tabular}{|c|c|c|c|c|}
\hline Area Name & $\begin{array}{l}\text { Season } \\
\text { Applied }\end{array}$ & $\begin{array}{l}\text { Depths } \\
\quad \text { in } \\
\text { territory }(\mathrm{m})\end{array}$ & $\begin{array}{l}\text { Expected Mean } \\
\text { Velocity }(\mathrm{m} / \mathrm{s})\end{array}$ & $\begin{array}{c}\text { Regression } \\
\text { Polynomial } \\
\text { shown }\end{array}$ \\
\hline \multirow{4}{*}{ ECS } & \multirow{2}{*}{ Summer } & 120 & 1526.3 & \multirow{2}{*}{ Fig.2a } \\
\hline & & 107 & 1527.7 & \\
\hline & \multirow{2}{*}{ Autumn } & 120 & 1527.3 & \multirow{2}{*}{ Fig.2c } \\
\hline & & 112 & 1526.4 & \\
\hline \multirow{2}{*}{ TEM } & \multirow{2}{*}{ Summer } & 116 & 1525.2 & \multirow{2}{*}{ Fig.15 } \\
\hline & & 90 & 1529.2 & \\
\hline \multirow{3}{*}{ MHC } & \multirow{3}{*}{ Summer } & 300 & 1513.6 & \multirow{3}{*}{ Fig.3a } \\
\hline & & 250 & 1515.2 & \\
\hline & & 200 & 1517.3 & \\
\hline CHS-E & Summer & 160 & 1522.0 & Fig.10a \\
\hline \multirow{2}{*}{ CHS-W } & \multirow{2}{*}{ Summer } & 138 & 1523.5 & \multirow{2}{*}{ Fig.11 } \\
\hline & & 120 & 1526.0 & \\
\hline $\mathrm{CHV}$ & Summer & 200 & 1519.7 & Fig.14a \\
\hline
\end{tabular}

\section{CONCLUSION}

At least 5 major types of acoustic profiles were defined in the offshore regions of northern Taiwan in summer or autumn season. Each type can be represented by a fitted polynomial curve estimated by the least-squares regression method, respectively. Although complex pattern of acoustic profiles had been observed in this study implying the spatial and seasonal oriented characteristic in the continental shelf, calibration can be done without too much care about how exactly the polynomial matches with the observed profiles in-situ. Using the regressed polynomial and following the calibration algorithm supplied in this study, one can properly correct any bathymetric measurement numerically. Otherwise, one may use a valid expected mean velocity at the value $1527 \mathrm{~m} / \mathrm{s}$ in the East China Sea Shelf, $1523 \mathrm{~m} / \mathrm{s}$ in the Chilung Shelf, or $1515 \mathrm{~m} / \mathrm{s}$ in the Mien-Hua Canyon/Chilung Valley in the vicinities of shelf 
territory. In the areas merely on the shelf surface, sounding results may be obtained with fine accuracy of less than $0.2 \%$.

Acknowledgements We would like to express our appreciation to the Data Bank of Marine Instrument Center, National Science Council of the Republic of China (former Data Bank of the Ocean Science Center) giving permission in using the CTD data in the year of 1994. We also thank Dr. Joe Wang who kindly helped us converting the CTD data into the acoustic profiles. In addition, L.-F. Chiu, P. -K. Liu, and H. -M. Lee are acknowledged for their help in processing, comparing the data sets, generating the drawings, and typing the Tables.

\section{REFERENCES}

Carter D. J. T., and J. Sherwood, 1980: Computerized Version of Echo-Sounding Correction Tables (Third Edition). Hydrographic Department, Ministry of Defense, Admiralty Chart Agents.

Del Grosso, V. A., 1973: Tables of the speed of sound in open water. J. Acoust. Soc. Amer., 53, 1385-1401.

Honeywell ELAC, 1990: Portable Hydrographic Survey Sounder LAZ4100, Operating Insuctions, BH 44362 8000E, Honeywell-Elac-Nautik GMBH, p2.08-2.09.

Hsu, S. K., J. C. Sibuet, S. Monti, C. T. Shyu, and C. S. Liu, 1996: Transition between the Okinawa Trough backarc extension and the Taiwan collision: new insights on the southernmost Ryukyu subduction zone. Mar. Geophys. Res., 18, 163-187.

IHO Standards for Hydrographic Surveys, 1987: Special publication no.44, 3rd edition, International Hydrographic Organization.

IHO Standards for Hydrographic Surveys, 1996: Special publication no.44, 4th edition, International Hydrographic Organization.

Liu, C. S., S. H. Liu, S. E. Lallemand, N. Lundberg, and D. L. Reed, 1998: Digital elevation model offshore Taiwan and its tectonic implications. TAO, 9, 705-738.

Lu, R. S., J. W. Ku, L. Tang, and F. C. Lin, 1978: Computer programs for the geophysical data reduction. Institute of Oceanography, National Taiwan University, Special publication no.20, 64pp.

Matthews, D. J., 1939: Tables of the velocity of sound in pure water and seawater for use in echo-sounding and sound ranging. Printed in England for Hermajesty's Stationery Office by A. Wheaton \& Co., Ltd., Exeter, 3-52.

Shyu, C. T., 1982: Corrections for the depth measurement in the offshore area of Taiwan. ACTA Oceanographica Taiwanica, 13, 69-83.

Shyu, C. T., 1984: Corrections for the depth measurement in the area of Taiwan (in abstract). Marine Geophys. Res., 7, 319-322.

Song, G. S., and Y. C. Chang, 1993: Comment on naming of the submarine canyons off northeastern Taiwan: a note by Ho-Shing Yu (1992). ACTA Oceanographica Taiwanica, 30, 77-84.

Song, G. S., and M. P. Chen, 1994: Final report of Bathymetry investigation offshore northeastern Taiwan, Bathymery Chart scaled in 1:150,000 included, National Science Coun- 
cil (in Chinese).

Song, G. S., Y. C. Chang, C. P. Ma, 1997: Characteristics of submarine topography off northern Taiwan. TAO, 8, 461-480.

Song, G. S., C. P. Ma, H. S. Yu, 2000: Fault-controlled genesis of the Chilung Sea Valley (northern Taiwan) revealed by topographic lineaments. Marine Geology, 169, 305325.

Wessel, P., W. H. F. Smith, 1991: Free software helps map and display data. EOS Trans. $A G U, 72,441-446$.

Yu, H. S., and G. S. Song, 1993: Submarine physiography around Taiwan and its relation to tectonic setting. J. Geol. Soc. China, 36, 139-156. 